Civil Engineering

Volume 168 Issue CE4

Mantra to method: lessons from

managing innovation on Crossrail, UK

DeBarro, MacAulay, Davies, Wolstenholme,

Gann and Pelton
Proceedings of the Institution of Civil Engineers Civil Engineering 168 November 2015 Issue CE4 Pages 171-178 http://dx.doi.org/10.1680/cien.15.00008 Paper 1500008

Received 19/02/2015 Accepted 08/06/2015

Published online 18/08/2015

Keywords: project management/railway systems/

transport management

Published with permission by ICE under the CC-BY license (http://creativecommons.org/license.by/3.0/)

\title{
Mantra to method: lessons from managing innovation on Crossraill, UK
}

1 Tim DeBarro BEng, MAPM, RPP Consultant, Nichols Group, London, UK

2 Samuel MacAulay BBus, PhD Research Fellow, UQ Business School, University of Queensland, St Lucia, Australia

3 Andrew Davies BA, MA, DPhil Professor, University College London, London, UK
4 Andrew Wolstenholme OBE Chief Executive, Crossrail Ltd, London, UK

5 David Gann CBE, CEng, FICE, FCGI

Vice President and Professor, Imperial College London, London, UK

6 John Pelton MBE

Strategic Projects Director, Crossrail Ltd and CH2M Hill, London, UK
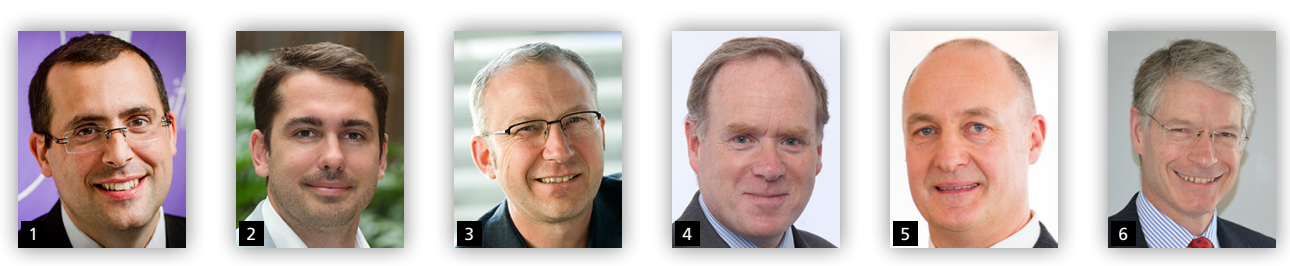

This paper describes how the $\mathbf{f 1 4 . 8}$ billion Crossrail project in London, UK developed and implemented an innovation strategy to support the delivery of the project. The strategy was designed to encourage the supply chain to develop and apply genuinely beneficial new products, processes and services - then to ensure these were shared throughout the project. The authors identify the steps taken, the managerial process created and the lessons learnt in developing and implementing the strategy. The aim is to contribute to a wider discussion on innovation in the infrastructure community: shifting from mantras about the intrinsic benefits of innovation to evidence about the most effective methods for managing it.

\section{Introduction}

Innovation and megaprojects can seem strange bedfellows. Nevertheless, reports from Latham (1994) through to Construction 2025 (HMG, 2013) have highlighted the criticality of innovation to deliver these projects successfully.

Innovation is, however, often perceived as a risky and uncertain activity and clients can be averse to these twin features of economic life. This paper examines how Crossrail managed these tensions during the development of its innovation strategy.

The word innovation is routinely quoted as a universal cure for the poor performance of the UK construction industry. Too often the word is repeated until it becomes a mantra, with little understanding of how it will be developed and applied to improve construction projects

Innovation is defined as a novel product, process, service or system of organisation that changes the prevailing order of an organisation, market or society (Dodgson et al., 2008; Van de Ven, 1986). It ranges from radically new ideas, which transform the practices and structures of existing institutional environments, through to incremental improvements to existing products, processes and services.

Written by key researchers and practitioners involved in establishing Crossrail's innovation strategy (Crossrail, 2012), this paper describes Crossrail's evolution from 'mantra', when the vision of an innovation strategy was first articulated, to 'method', when it was implemented in practice.
It is now widely accepted that improvements in performance in most industries depend on innovation (Dodgson et al., 2008, 2014), whereas in the world of infrastructure megaprojects, innovation is often avoided due to its association with uncertainty and increasing costs (Van Marrewijk et al., 2008).

Sponsors, clients and contractors are reluctant to introduce novel ideas and innovative approaches. They often seek to minimise the risks involved by relying on tried-and-tested techniques, established routines and reliable proven technologies (Hansford, 2014).

Against this backdrop, it is important to note that there are a number of UK megaprojects that have begun to take steps towards a more systematic approach to innovation. Much of this work has focused on the front-end contracting, such as BAA's Terminal 5 agreement and London Underground's innovative contractor engagement. Crossrail's distinct contribution to this movement has been to develop a systematic process to mobilise and manage innovation during the construction of the project.

The paper is divided into the following sections. Section 2 explains the challenges associated with delivering a megaproject and argues that systematically managing innovation can help to overcome them. These challenges stem from: the complexity of coordinating innovation activity across huge supply chains; the temporary nature of the project; and the way these projects are traditionally funded.

Section 3 describes how Crossrail has sought to meet the challenges, specifically the organisational structures and procedures put in place to encourage and identify innovation, select and resource valuable innovation opportunities and drive implementation and impact. 
Mantra to method: lessons from managing

innovation on Crossrail, UK

DeBarro, MacAulay, Davies, Wolstenholme, Gann and Pelton
Section 4 uses data on innovations that have been invested in, shared or not pursued to provide an analysis of the programme's performance. Finally, the paper concludes by reviewing the performance throughout the first year of implementation and discusses the lessons learnt.

\section{Mantra}

Crossrail is currently Europe's largest civil engineering project. The budget for the project is $£ 14.8$ billion and the railway is scheduled to open in phases starting in 2017. This complex 'system of systems' project (Shenhar and Dvir, 2007) involves the construction of a commuter and metro suburban railway from Reading and Heathrow airport in the west, beneath central London, to Shenfield and Abbey Wood in the east (Figure 1).

The $118 \mathrm{~km}$ railway system includes $21 \mathrm{~km}$ of central twinbore $6.2 \mathrm{~m}$ diameter rail tunnels underneath central London and construction of nine new stations. On completion, Crossrail will increase London's railway passenger capacity by $10 \%$. It is expected that 200 million passengers a year will use the new link. Crossrail services through the central London tunnelled section will open in September 2018, and a full service will be operating from late 2018.

During the peak period of construction in 2014, there were over 75 companies directly supporting the delivery of Crossrail with over 10000 people working on the programme. These numbers underline the scope for leveraging innovation from the many actors and stakeholders involved in such a large and diverse project supply chain.

In 2013, there were over 20 main (tier 1) contractors undertaking vast construction projects throughout London as part of the Crossrail delivery programme. Many of the contractors were facing similar challenges. Crossrail was keen to support the supply chain to improve on current best practice by developing innovative new ways of working. To do this, Crossrail had to find a way of encouraging its supply chain to develop and implement innovative new products, services and processes to deliver the railway by 2018 .
Previously, discrete pockets of innovation were occurring within the programme, motivated by efforts to overcome delivery challenges and respond to opportunities. However, the people involved rarely recognised that they were engaged in innovation; instead they considered it as just 'what they did'. As a result, it was observed that innovation occurring in these pockets was often managed in an ad hoc manner, lacking appropriate strategic direction, sponsorship and access to funds.

For instance, the Crossrail tunnel engineering department helped the Crossrail sustainability manager develop an innovative idea that paired the tunnel segments with under-flooring heating pipework (Nicholson et al., 2014), a recirculation system and heat exchanger to extract the geothermic heat around the tunnel (Figure 2). It was anticipated that the solution would cool the tunnel environment and provide a renewable energy source for local over-site developments.

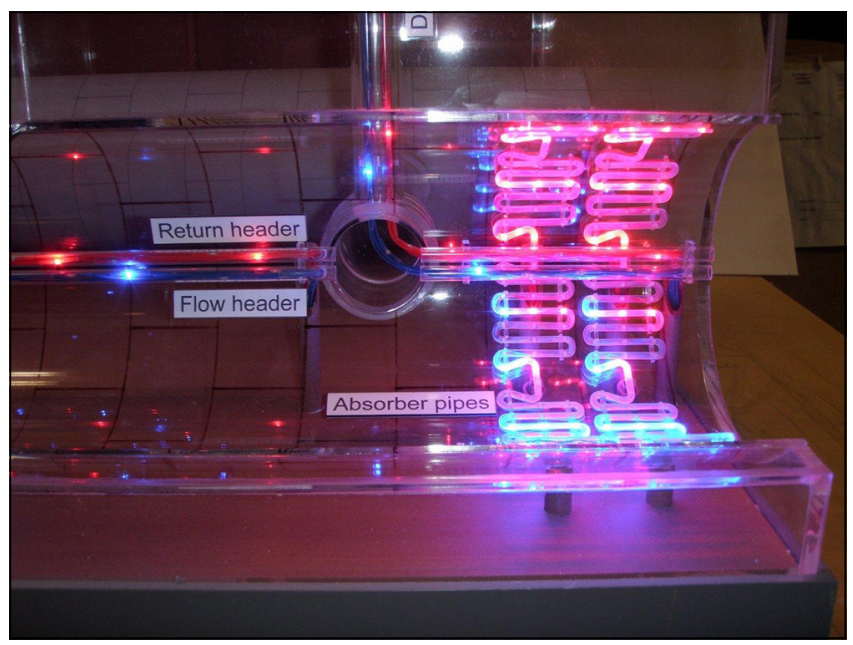

Figure 2. Tunnel energy segment concept model - an example of discrete pockets of ad hoc innovation that used to occur on the programme

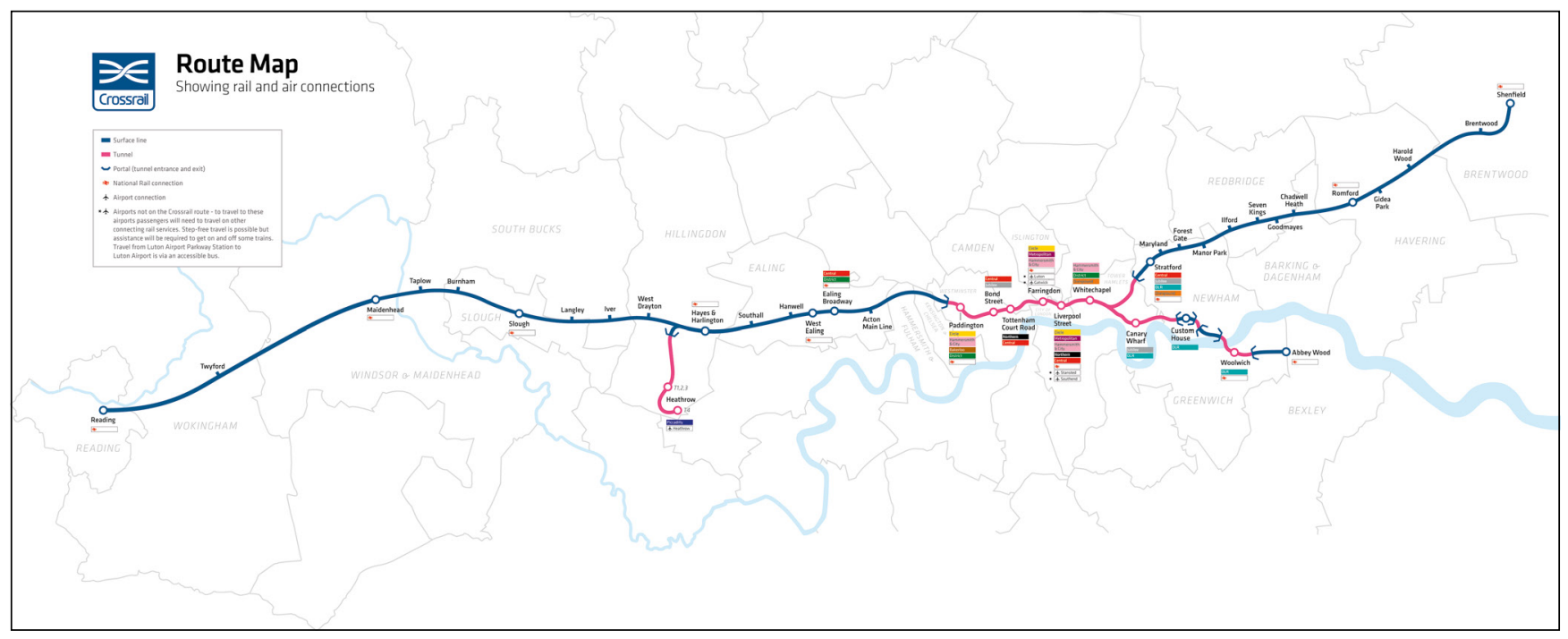

Figure 1. Crossrail is Europe's largest civil engineering project, providing a $118 \mathrm{~km}$ east-west commuter railway for London 
This idea was developed without leadership support, funding or collaboration from the tunnelling contractors.

The lack of structure had important consequences for Crossrail's ability to deliver value for money. Investment sunk into local innovation efforts was not being fully exploited and the benefits were not being systematically transferred across the programme or the broader industry.

Crossrail's supply chain was selected for its demonstrable ability to solve the difficult challenges the project faced. However, senior management at Crossrail did not believe they could expect the supply chain to accept the obligation of coordinating and sharing innovation with the rest of the Crossrail programme. They saw this responsibility resting solely with Crossrail because, at a programme level, it was Crossrail that had the reach to coordinate across the supply chain and the fiduciary duty to guide innovation towards areas of strategic importance.

The main obstacle to coordinating innovation activity and investment across the programme was the inherent complexity of the project ecosystem. This task was made more complicated by the large number of joint ventures and partnerships formed to deliver unique packages of the programme (approximately 20). The commercial incentives relating to these packages often vary and the contractual models used to procure them generate a diverse combination of local cultures and structures. It was therefore crucial to establish the organisational mechanisms and culture that would enable resources for innovation to be mobilised across this complex ecosystem.

The world's leading innovators such as Google, Apple, GlaxoSmithKline and Toyota have developed corporate strategies to support innovation and have provided investment for innovation over many years. This reliance on innovation is much less prevalent in the construction industry, which has been characterised by low margins, risk and change aversion and constantly reforming project delivery organisations (Wolstenholme, 2009).

At the time Crossrail was developing its thinking on innovation, there were signs that the dynamics were changing. The value of strategically managing and investing in innovation was being recognised both by industry and government. The UK infrastructure cost review (Infrastructure UK, 2010), for example, identified investing in innovation as a key point of leverage for reducing the high cost of UK infrastructure.

Some of the firms in Crossrail's supply chain have grasped the importance of strategically managing innovation, valuing the formal innovation management processes, and have developed structured programmes for investing in and managing innovation. Collaborating with universities and small and medium enterprises, these large firms are supporting and nurturing the long-term development of innovative solutions to differentiate themselves from their competitors, ensure their survival and maximise the opportunity for growth.

In contrast to the firms that have developed innovation strategies, a megaproject like Crossrail is a temporary organisation formed (in this case by government) to deliver a one-off outcome. Once completed and handed over to the operator and maintainer, the delivery organisation ceases to exist and dissolves. Typically the cost of construction is separated from the in-service operational costs.

The motivation of these temporary organisations to innovate is, therefore, fundamentally different from that of a permanent organisation. Temporary organisations like Crossrail are innovating to ensure the outcome is delivered safely, to schedule, to budget and that a quality outcome is delivered without complication or incident which could tarnish the project. Innovation for them is not about survival, but focused on 'dying' more quickly and gracefully.

The complex organisationalstructureand differencein organisational purpose had a fundamental influence on the development of Crossrail's innovation strategy. Crossrail began viewing the megaproject as an ecosystem of many diverse and interconnected organisations and thus focused on building the organisational mechanisms and culture required to develop and broker innovation across different parts of it.

\section{Method}

Defining the vision and identifying the unique challenges that Crossrail faced was the first critical step to developing a method for managing innovation. This work was distilled into an innovation strategy document.

It was widely accepted that the strategy document alone would not be sufficient to raise the awareness and gain the necessary support for the programme. Rather, effort needed to be expended at all levels of the organisation to shift the culture away from one of parochialism and towards one that prized collaboration; one where it was normal to collaborate across departmental, site and company boundaries in the pursuit of innovation. This transformation was advocated through a cascading series of 'boots on the ground' engagements between a small central team of innovation champions and different organisational units (e.g. sites and departments).

Engagement had to be tailored to each project, department and company to ensure relevance to their local objectives and that these were clearly aligned with the objectives of the innovation programme.

For example, the motivation of the Crossrail environment department to engage with the innovation programme to promote and cascade innovative solutions across the project to drive performance improvement were very different to those of the project teams responsible for constructing the new Crossrail stations, who were pursuing innovative solutions to overcome the challenges of integrating their buildings within existing London Underground infrastructure.

Driving the cultural shift through Crossrail required leadership to communicate objectives visibly and coordinate programme-wide effort. Supporting the bottom-up drive with commitment from the senior leadership of Crossrail was critical to the success in the early days of the programme. Crossrail's chief executive is a clear and visible leader for the programme. His messages both internally and externally were part of a wider communications campaign to raise the awareness and purpose of the programme.

The social side of the change effort was also complemented by shifts in the economic incentives at play in the organisation. Crossrail introduced new key performance indicators into the existing contractual incentives of the programme partners (the Nichols Group, CH2M HILL and Aecom) and delivery partners (led by Bechtel with CH2M HILL and Systra) supporting the delivery of Crossrail to help align the coalition around the innovation strategy.

Assessing the extent to which an organisation is innovative is difficult to quantify. Crossrail decided to measure the extent to which innovation was being developed and adopted by the programme. Tracking the number of ideas that were implemented against the total received, or in other words the rate of conversion, could be easily quantified and provided an incentive to identify and develop ideas of quality that could be implemented. 


\subsection{Governance and funding}

The programme required a simple, but structured process and governance model for identifying innovation, selecting the most promising ideas and allocating the resources required to transform ideas into innovations.

There were two main drivers. First, the need to avoid a lengthy change-management governance process which would be likely to stifle the development of innovation. Second, seed funding was often required to progress an idea sufficiently to demonstrate its value prior to large-scale deployment.

To support innovation effectively, a dedicated funding model was created to invest in innovation and provide an efficient method of evaluating the ideas with an appropriate level of governance to satisfy the expenditure of public funds.

Crossrail invited the chief executives of the tier 1 suppliers to support the emerging innovation programme. Eleven chief executives from Crossrail's supply chain (BAM Nuttall, Costain Ltd, Dragados, Ferrovial, Hochtief, Kier, Laing O'Rourke, Murphy, Morgan Sindall, Skanska and Vinci) subsequently committed a modest contribution to a common fund that was match-funded by Crossrail. The purpose of the fund was to invest in innovation collectively, share innovative practices in an 'innovation club' and create an ecosystem where all can work together to identify and develop opportunities for innovation on Crossrail and the broader industry.

The Crossrail innovation forum was then established as the executive-level group that provided strategic direction to the innovation programme on the governance and investment of the innovation programme. Its primary role was to ensure that the trajectory of the innovation programme remained aligned with that of the overarching organisational strategy.

The forum typically met once per quarter. It principally consisted of four representative groups with a Crossrail non-executive director as its chairperson

- Crossrail executive - members of the executive team

- innovation programme manager

- supply chain - senior representatives from two or three contractors which have direct interest in innovation

- academia - senior academics who act as 'neutral' brokers, helping shape the Crossrail innovation (and research) agenda and providing expert advice.

An innovation working group was also established, chaired by Crossrail's strategic projects director, and was made up of the same supply chain members that attend the Crossrail innovation forum, the innovation programme manager and representatives from Imperial College London. The primary objective of the working group is to steer and govern the innovation programme and recommend investment opportunities to the innovation forum.

Investment rounds were scheduled twice a year to ensure that investment decisions were made within the context of a portfolio of comparative options and to ensure sufficient time was allocated to mature ideas. This periodic cycle created a rhythm to the innovation programme that enabled project teams to focus their efforts towards the generation of new ideas. It also provided an impetus to prepare investment applications before the evaluation deadline.

But the cycle also created a tension because opportunities for innovation can be time sensitive and these would, under normal circumstances, have had to wait until the next evaluation period, by which time the opportunity may have passed. To mitigate this risk, the programme manager was given the authority to award seed fund investment. Seed funding was carefully monitored due to the potential for this funding route to become the 'easy' option, which would undermine the benefits of making funding decisions as part of a portfolio of innovation projects.

\subsection{Structure}

A small core team was funded by Crossrail to manage and support the innovation programme. Figure 3 illustrates the overall management structure of the programme.

The innovation team is responsible for nurturing an environment in which innovation can prosper. It is responsible for the capture, review, selection, implementation, programme and portfolio management and reporting of the innovation ideas for Crossrail.

The programme manager provides the strategic management of the innovation programme to ensure the objectives of the Crossrail innovation strategy and innovation forum are delivered. The project manager is responsible for the successful delivery of invested projects as directed by the programme manager.

The innovation coordinator is responsible for raising awareness and understanding of the programme, facilitating collaboration throughout Crossrail and supporting the identification, development and diffusion of innovation ideas.

Finally, the innovation reporting officer is responsible for the production of the monthly innovation programme reports and provided scheduling capability during the assessment or implementation of innovation ideas. They develop and administrate the online tools used to facilitate collaboration throughout Crossrail.

To facilitate implementation, ideas needed to be reviewed efficiently to understand quickly their true value to Crossrail and/ or the industry and the constraints to their development. Crossrail also recognised that it needed to improve the way individuals collaborated throughout a large, multi-organisational megaproject.

The chosen approach needed to be mindful that collaboration can consume scarce resources and budgets, both of which are tightly controlled within Crossrail. To overcome this, young professionals from the Crossrail early career professional programme and from a variety of disciplines were encouraged to get involved because they were keen to gain valuable experience with such a high-profile activity and had more time to engage in it than their more senior managers.

Approximately 50 individuals across each of the projects and functional directorates became innovation champions. These champions provided a primary point of connectivity to the innovation network, to reach back into their teams and connect innovators from across the community with expertise within their project team or directorate and to provide feedback on ideas.

The project champions were encouraged to establish an equivalent contractor champion to partner with and share the drive for innovation activity on their project. On individual projects where innovation was valued as a way to contribute towards the successful outcome of that project, a working group was formed that included representatives of key subcontractors, the principal contractor and Crossrail. These groups reviewed emerging project risks and ideas, prioritised resource capacity accordingly and reported to the senior project management team.

In this way, Crossrail built a network of collaborators among its partners in its supply chain, including universities, railway operators, users and other stakeholders, in order to facilitate the identification and evaluation of innovation ideas. 


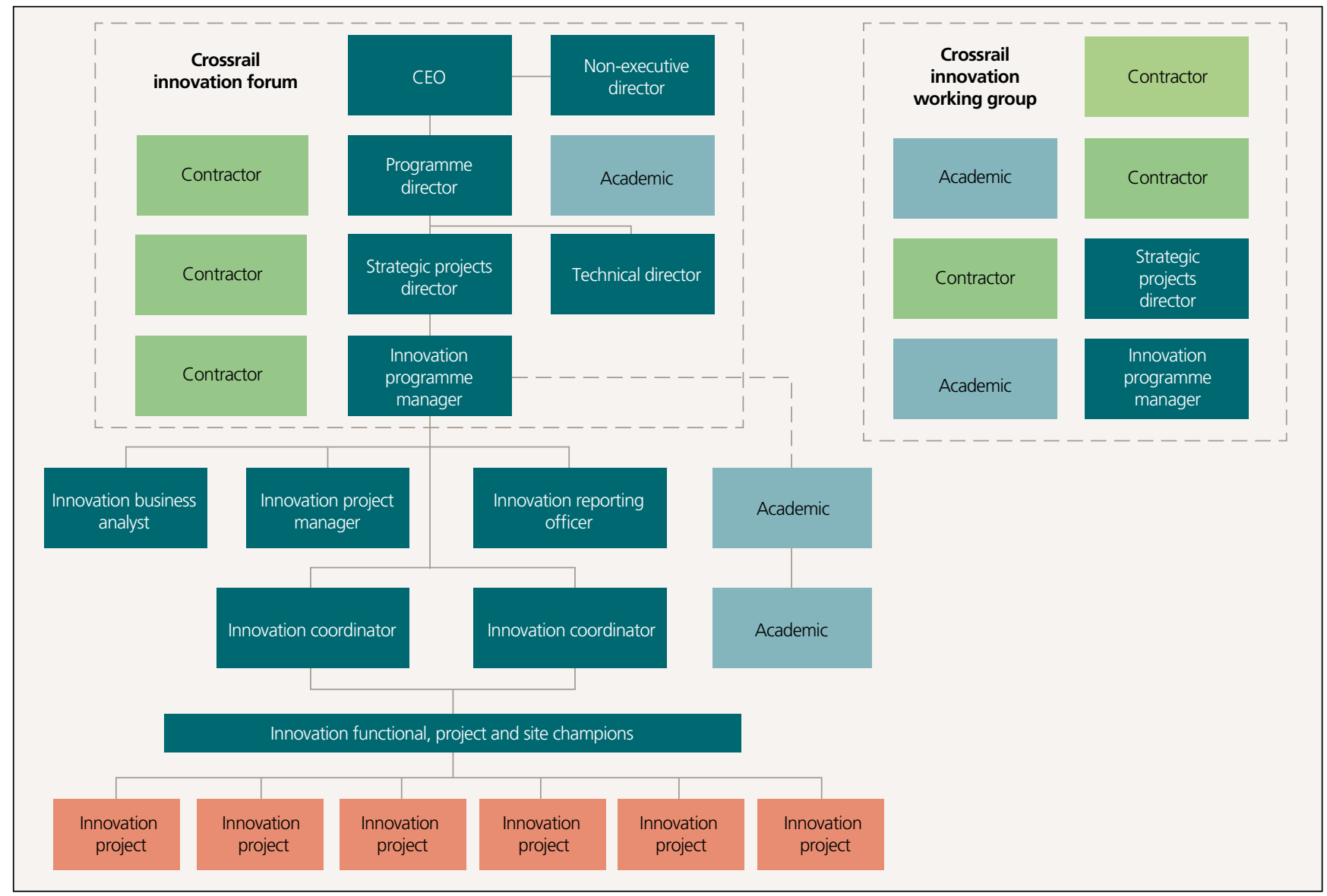

Figure 3. Organisational structure for Crossrail's innovation programme

\subsection{Process}

The Crossrail innovation process follows five simple stages as shown in Figure 4.

In stage 1 , ideas can be submitted by any organisation working on Crossrail by way of a members-only website, www.innovate 18 . co.uk. The innovator is required to complete a short form that provides a summary of the idea and its application.

In stage 2 , the associated project or functional champion and innovation coordinator then build up a detailed understanding of the idea through direct discussions with the innovator and through engaging with the wider innovation community, if necessary creating a task group to manage the development of the idea.

Through periodic reviews the progress of an idea is assessed and the champion and innovation team can decide to

- continue to develop the idea, termed the 'discovery' phase, for further investigation by the idea task group

- archive or 'park' the idea for future consideration

a promote the sharing of the innovation across the programme

- agree to implement the innovation (i.e. funding is not required)

- apply to the innovation programme manager for seed fund investment

- submit the idea into the next evaluation round (i.e. where largescale investment is required).
Stage 3 is the innovation evaluation competition, and is only open for a limited period. Successful entries are likely to be (but not always) supported by a project manager, sponsored by the relevant Crossrail functional directorates and by the most appropriate director.

In stage 4 the Crossrail innovation working group reviews all entries and selects a shortlist of recommended innovation ideas for investment. Any entry that is shortlisted by the working group but seeks funding beyond the delegate authority limits of the working group or is considered to be complex (e.g. it involves the collaboration of two or more Crossrail directorates and/or imposes risk to the programme) is passed up to the Crossrail innovation forum for further review and potential escalation into Crossrail's standard change-management processes.

In stage 5 , once ratified by the Crossrail innovation forum, a project manager is assigned to deliver the innovation project and success parameters are agreed and a delivery strategy and reporting mechanisms are approved by the innovation programme manager.

A website was developed to provide a simple way to share project information freely. Access to the website was restricted to those companies that had invested in the programme. It provided the entire Crossrail community with the opportunity to discuss emerging ideas, find other like-minded people to help develop ideas and contribute to a searchable library of one-page summaries of implemented innovations 


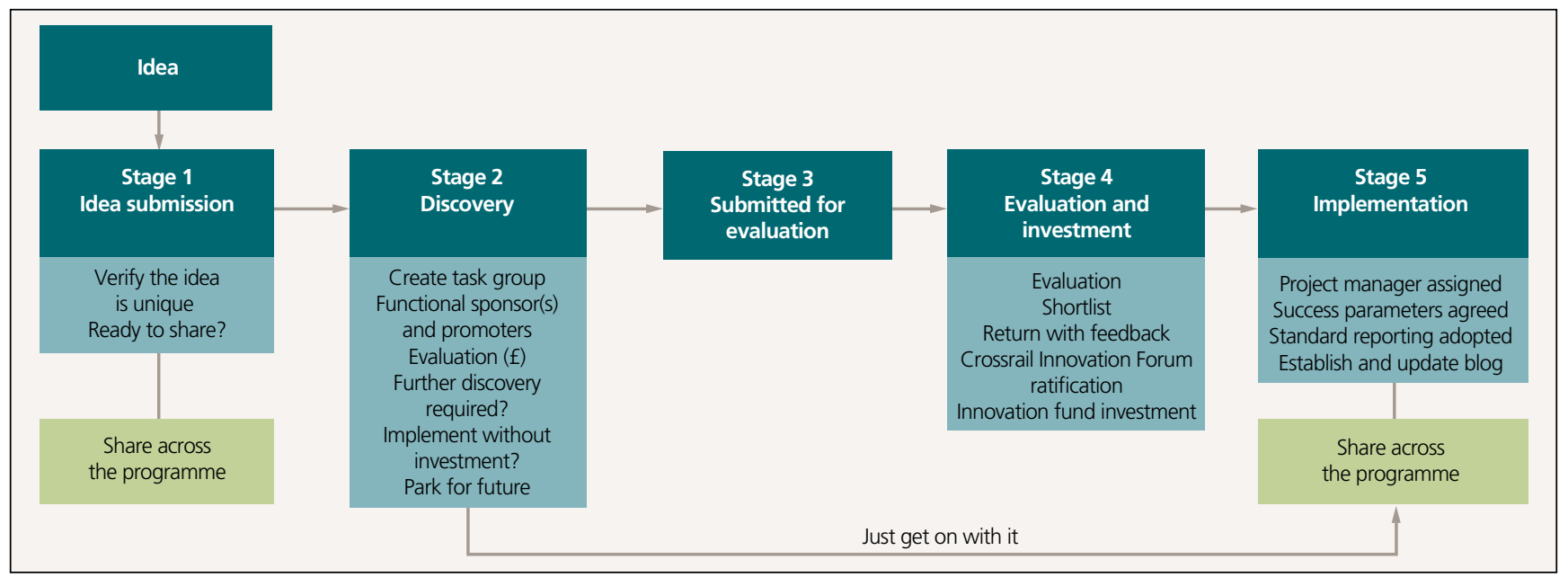

Figure 4. The five stages of the innovation process

\section{Performance and outcomes}

The innovation programme undertook a 3-month pilot in October 2012 with three project teams at Liverpool Street, Paddington and Connaught tunnel. The pilots were designed to trial the processes and systems developed to manage innovation. Lessons learned were collected throughout and discussed at a close-out meeting with key stakeholders. The outcomes influenced the processes, governance and structure described in Section 2.

The programme was then launched across the entire organisation in April 2013 and in the first 12 months of the programme over 400 ideas were submitted, of which over 180 were developed into innovations and published in the online library found at www.innovate18.co.uk. The decision to focus on drawing up and sharing innovative practices/products in the early development of the programme proved to be critical to widespread engagement. It provided an immediate achievable objective for everyone and highlighted an immediate benefit to organisations where they would receive ten innovations from the community for every one they shared.

Figure 5 illustrates the status of the programme over the first 18 months, tracking the number of ideas throughout this period and the status of the total number of ideas received in April 2014.

- Ideas in discovery - total number of ideas that are being developed and investigated with the support of the innovation team and the network of technical specialists.

- Total published - total number of innovations published on www.innovate18.co.uk.

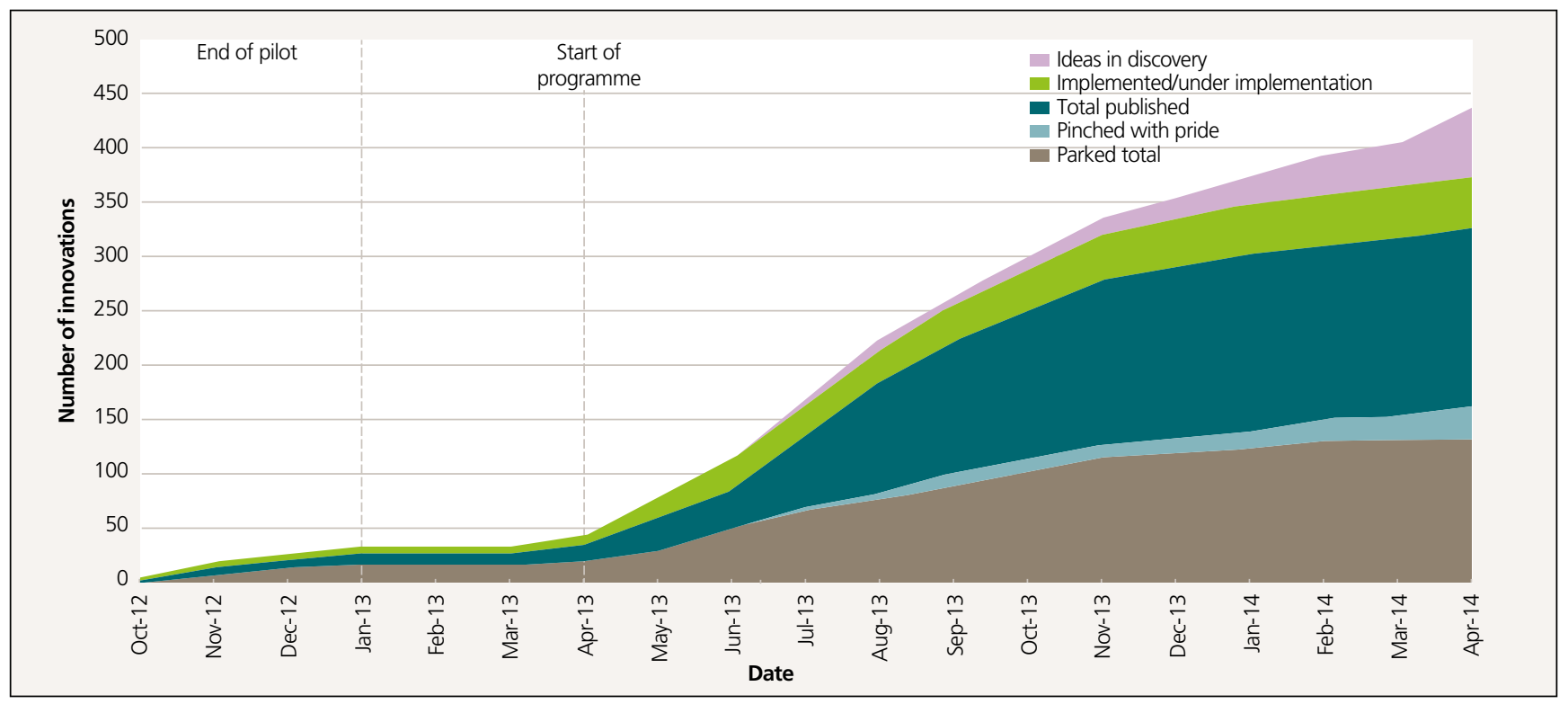

Figure 5. In the first 12 months of the programme over 400 ideas were submitted, of which over 180 were developed into innovations and published at www.innovate18.co.uk 
Civil Engineering

Volume 168 Issue CE4
Mantra to method: lessons from managing

innovation on Crossrail, UK

DeBarro, MacAulay, Davies, Wolstenholme, Gann and Pelton
- Implemented/under implementation - total number of innovations that have been or are currently being implemented across the programme but not yet published on www.innovate18.co.uk.

- Pinched with pride - total number of innovations published on www.innovate 18.co.uk and that have been adopted by other projects.

- Parked total - total number of ideas archived or 'parked' the idea for future consideration.

The contractors identified the importance of demonstrating their innovative capability and culture. This involved proactively pursuing innovative solutions that drive improved performance and demonstrating the benefits of openly sharing their capability to add value to this and subsequent projects.

Crossrail needed to establish a way to motivate the people involved in one project to adopt innovations generated by others. A league table was published identifying the most innovative projects (Figure 6). Projects were recognised for idea generation, implementing innovations, publishing innovative solutions and even those adopted or 'pinched (with pride)' from other sites.

The inter-project competition saw contractors and client delivery teams begin to search for opportunities to adopt the best innovations from other projects and identify future challenges on their project to focus their own innovation efforts. These discussions inspired the project team at Bond Street to create an innovation working group that included Crossrail staff and focused on driving efficiencies into the excavation of the western ticket hall.

The group scored an early success by identifying that adopting the use of a telescopic clamshell excavator, previously trialled and the outcomes shared by the Paddington station project, would improve the rate of excavation from the traditional technique of an excavator, skip and crane approach $\left(48 \mathrm{~m}^{3} / \mathrm{h}\right)$ to $54 \mathrm{~m}^{3} / \mathrm{h}$ (Figure 7 ).

The extent to which engagement was secured throughout the projects was varied. A wide range of factors appeared to be driving engagement levels. While a systematic investigation of these drivers was beyond the scope of this study, engagement seemed to be lower when there was financial or programme stress.
During the first two evaluation periods in the summer of 2013 and winter of 2014, 23 projects were selected for $£ 336910$ of investment. Examples of these projects include

- an investigation into the reuse of London Clay as a lightweight aggregate to create lightweight concrete

- creating customised messages on the back of safety gloves to provide construction projects with a bespoke behavioural change programme

- developing software to enable the differentiated control of mobile devices in segregated construction plant zones from other zones (e.g. pedestrian walkways) within an underground construction environment (based on iBeacons technology).

A prerequisite of investment is that information and knowledge associated with the innovation projects (e.g. the success of an innovation idea) must be published on www.innovate18.co.uk to ensure it can be shared across the supply chain. Codifying innovations, and their performance, in this manner also makes it easier for future projects to build on the work done at Crossrail.

Using the data received as part of the contractor audit process, Crossrail's internal assurance team compared the 'combined' key performance indicator score (that summarises each contractor's performance against health, safety and environment, schedule and cost) with the data from the innovation programme. A correlation was noted between project performance and the number of implemented innovations on the project. While this is an interesting correlation, an alternative explanation for this finding could be that better-performing projects may have more capacity to allocate more discretionary effort to innovation. Investigating this causality would be an important step for future research.

The ability to implement innovative ideas on Crossrail is constrained by the tight schedule and need to complete the programme by December 2018. There are distinct phases or temporary opportunities within which ideas can be successfully developed and implemented, after which the opportunity to develop an innovation may be lost completely. This is termed the idea's 'horizon'.

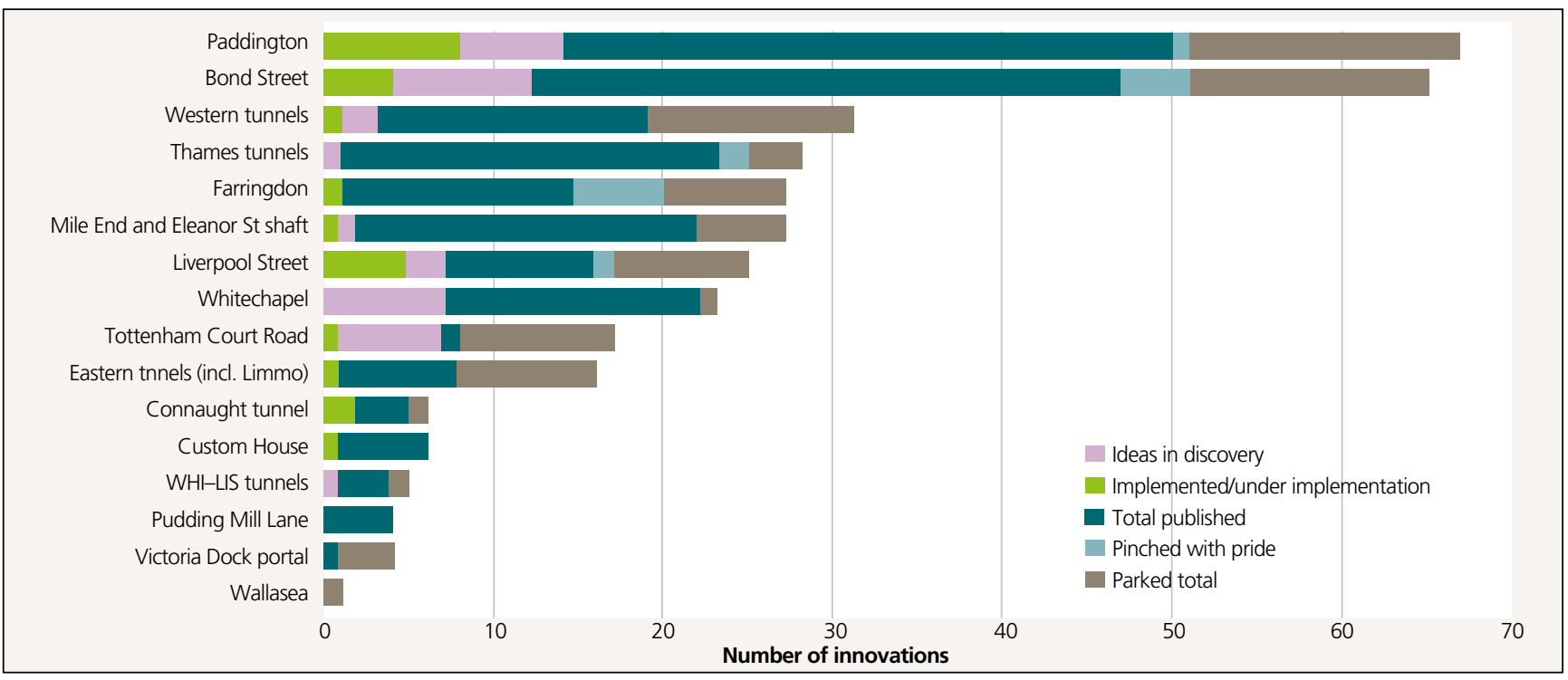

Figure 6. A league table was published identifying the most innovative projects - this also helped to encourage projects to adopt innovations generated by others 
Civil Engineering

Volume 168 Issue CE4
Mantra to method: lessons from managing

innovation on Crossrail, UK

DeBarro, MacAulay, Davies, Wolstenholme, Gann and Pelton

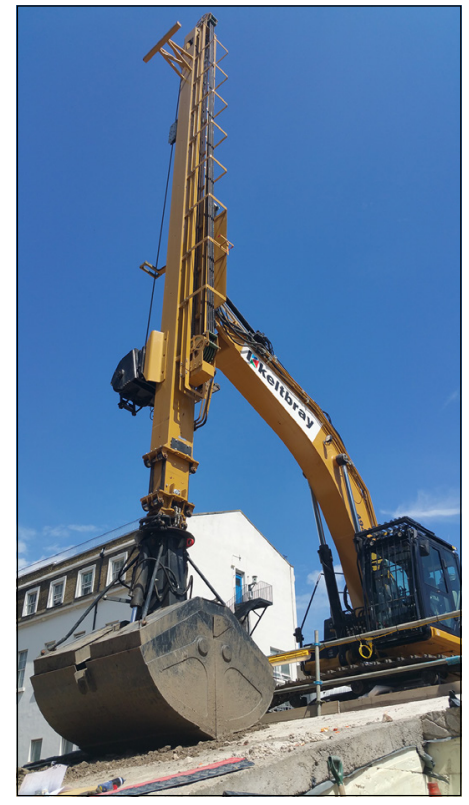

Figure 7. The innovation programme led to use of telescopic clamshell excavators on other projects following successful trials at Paddington, which found excavation rates increased from $48 \mathrm{~m}^{3} / \mathrm{h}$ to $54 \mathrm{~m}^{3} / \mathrm{h}$

Members of the project now recognise that innovation provides a mechanism to help each integrated team achieve its objectives. The Crossrail innovation coordinators, in particular, provided personal contact and real energy on the ground to help make this happen.

The value of the innovations supported and implemented across the programme have largely benefited the contractors involved by increasing efficiencies in the construction schedule, improving the environmental performance of the project and mitigating risk by eliminating health and safety hazards through the adoption of innovation. In many cases this also provided direct benefit to Crossrail - and most benefits were, in any case, effectively shared through the pain/gain share mechanisms within the NEC3 Engineering and Construction Contract used throughout the project.

\section{Discussion and conclusion}

This paper has described the challenges that Crossrail has had to overcome during its innovation programme's journey from 'mantra' to a 'method' for managing innovation. By ensuring that the extensive bottom-up engagement was supported by leadership at every level of the organisation, all communicating the same clear and simple objectives, the programme has succeeded in driving awareness and recruiting willing participants to build an innovation community with over 1000 members.

The programme is managed by a modest core team, but has relied heavily on the volunteer network of champions to stimulate the generation and filtering of ideas in an open and supportive environment, building confidence in the simple processes developed to manage systematically the development, evaluation, investment and implementation of innovation. It established a powerful new platform for sharing innovation-related information (e.g. problems out on site and new technological solutions) and mobilising the effort of the vast construction community building Crossrail.
The programme has nurtured and encouraged a culture where innovative ideas are valued, explored collaboratively and implemented in a systematic way. In doing so, the supply chain members have become more comfortable with the concept of the open innovation model in a megaproject and are more willing to share new practices and products openly within this ecosystem.

Crossrail is committed to capturing the lessons from implementing an innovation strategy and sharing them openly with organisations both involved and not involved in the project. Crossrail has been actively involved in these efforts and there now appears to be a growing desire to see the systematic management of innovation become an established feature of all future UK megaprojects. For example, the Thames Tideway tunnel is in the early stages of developing its own innovation strategy.

It is hoped that this paper will provide a benchmark and also inspire further investigation in areas, such as the structuring of project funding mechanisms (e.g. contingencies) to encourage innovation, alternative management approaches and the development of models for coupling the innovation efforts of major projects. In this way, the Crossrail experience provides a first step on the route towards fully exploiting the innovative potential available to the UK's construction industry.

\section{Acknowledgements}

The programme of research reported in this paper began while DeBarro was working on the Crossrail project and Davis and MacAulay were working at Imperial College London. The authors thank research participants from Crossrail for providing generous access to data during the research process. The research was conducted using matched funding provided by Imperial College London's innovation studies centre and Crossrail.

\section{References}

Crossrail (2012) Crossrail Innovation Strategy: Moving London forward. Crossrail, London, UK. See http://www.crossrail.co.uk/benefits/innovation (accessed 08/06/2015).

Dodgson M, Gann D and Salter A (2008) The Management of Technological Innovation: Strategy and Practice. Oxford University Press, Oxford, UK.

Dodgson M, Gann D and Philips N (2014) The Oxford Handbook of Innovation Management. Oxford University Press, Oxford, UK.

Hansford M (2014) Unlocking our chains. New Civil Engineer, 27 November. HMG (Her Majesty's Government) (2013) Construction 2025 - Industrial Strategy: Government and Industry in Partnership. The Stationery Office, London, UK. Infrastructure UK (2010) Infrastructure Cost Review. HM Treasury, London, UK. Latham M (1994) Constructing the Team. Her Majesty's Stationery Office, London, UK. Nicholson D, Chen Q, de Silva M, Winter A Winterling R (2014) The design of thermal tunnel energy segments for Crossrail, UK. Proceedings of the Institution of Civil Engineers - Engineering Sustainability 167(3): 118-134

Shenhar AJ and Dvir D (2007) Reinventing Project Management: The Diamond Approach to Successful Growth and Innovation. Harvard Business School Press, Boston, MA, USA.

Van de Ven A (1986) Central problems in the management of innovation. Management Science 32(5): 590-607.

Van Marrewijk A, Clegg SR, Pitsis T and Veenswijk M (2008) Managing public-private megaprojects: paradoxes, complexity and project design. International Journal of Project Management 26(6): 591-600.

Wolstenholme A (2009) Never Waste a Good Crisis. A Review of Progress since Rethinking Construction and Thoughts for Our Future. Constructing Excellence, London, UK. See http://constructingexcellence.org.uk/ resources/never-waste-a-good-crisis/ (accessed 08/06/2015) 